\title{
Development of Web- Based Nutritional Health Education Module
}

\author{
Eman R. El- Refaay ${ }^{1}$, Amel I. Ahmed ${ }^{2}$, Nagwa M. Salem ${ }^{3}$ \\ ${ }^{I}$ Demonstrator, Department of Community Health Nursing, Faculty of Nursing, Mansoura University, Egypt \\ ${ }^{2}$ Assist. Professor, Department of Community Health Nursing, Faculty of Nursing, Mansoura University, Egypt. \\ ${ }^{3}$ Lecturer, Department of community health Nursing Faculty of Nursing, Mansoura University, Egypt
}

\begin{abstract}
Young adulthood is a vulnerable period for weight gain and the health consequences of becoming obese. University years are a time of emerging identity and habit formation for young adults. During university years, individuals practice unhealthy eating patterns such as meal skipping, snacking, and fast food consumption. Eating pattern could be modified by providing valid nutritional information. The young adults used to obtain information from different internet websites.

Aim: The purpose of this study was to develop a web-based nutritional health education module.

Study design: A cross-sectional design was used to carry out this study at different faculties of Mansoura University. Total sample size of 650 university students involved in the study, in addition to a group of ten professional experts who were academic staff members and had experience in health education, online education and community health nursing. The Study was conducted throughout four stages, which were preliminary assessment stage, development stage of the web evidence- based nutritional health education module, dissemination stage, and evaluation of module's internal validation stage.

Results: The study showed that $94 \%$ of students had poor knowledge level about healthy diet and its components and $78.5 \%$ of students showed unsatisfactory dietary pattern. The developed Web-based nutritional health education module composed of five lessons. Each lesson included a number of nutritional health education messages that were illustrated in texts companied with attractive media. University students and experts described the module, as a comprehensive and attractive health education module that uploaded on an accessible and easy navigated website.

Conclusion: The developed web-based nutritional health education module was accepted to both university students and experts. The entire content that presented by using of multimedia fulfilled the nutritional health education needs of university students.
\end{abstract}

Keywords: Nutritional health education, Dietary pattern, University students, Web- based module, Evidencebased practice

\section{Introduction}

Young adult period that starts from age 18 to 25 years old usually is the university-studying period. Individuals' independent choices about lifestyle and health practices are built during this period ${ }^{(1)}$. University life plays an important role in placing young adults as nutritionally vulnerable group, while adequate nutrition is essential issue for a well health ${ }^{(2,3 \text {, and } 4)}$. However, during university years, individuals practice unhealthy eating patterns such as meal skipping, snacking, and fast food consumption ${ }^{(2,3)}$. Irregular meal patterns and consumption of high caloric snakes and fast food may contribute to overweight, obesity and other chronic diseases ${ }^{(5)}$. This dietary pattern of young adulthood may have long-term health implications into adulthood period $^{(6)}$. Fortunately eating behavior is a modifiable health behavior ${ }^{(2)}$. Knowledge, attitudes, beliefs, and food preferences are modifiable personal factors that influence eating behavior ${ }^{(7)}$. Young adults may try to modify their eating behavior by obtaining nutritional information from numerous channels, but not all of these channels are valid sources ${ }^{(8)}$. So that valid sources of health information should be provided for young adults via their preferred channels. The interacting via internet and web-based learning systems is an effective learning channel in the $21^{\text {st }}$ century ${ }^{(9,10)}$. The internet provides low-cost access to health messages for a large sector of people that stimulate their perceptions of autonomy ${ }^{(11)}$. Web-based learning provides a multimedia environment and support interactive communication ${ }^{(9)}$. Internet can provide many lifestyle interventions that concerning about diet, exercise, and smoking. Community health nurses as health educators provide health educational services to individual, families, and groups. They have effective role in the development of population based health education programs ${ }^{(12)}$.

Using of evidence-based practice approach that has a great attention in public health would be constructive in building nutritional health education. Evidence- based public health include six key components. The first and second keys are making decisions based on the best available scientific evidence and using data and information systems systematically. Third and fourth keys are applying program-planning frameworks and 
engaging the community in decision-making. The fifth key is conducting sound evaluation and finally disseminating what is learned ${ }^{(13)}$. Therefore, it was important to provide valid information about nutritional issues through information channel that is preferable to university student.

\section{Aim of the Study}

The study aimed to develop web- evidence based health education module for university student.

\section{Subjects and Methods}

\subsection{Study design:}

The study design was determined to be cross sectional design, which was selected for investigating the health education needs of university students. The study was conducted at 13 faculties at Mansoura University. The study subjects were university students and health education experts.

\subsection{Subjects and sampling}

Regarding to subjects and sampling, university students who involved in the study should be free from diseases/ health condition that require special dietary regimen or affect the body weight. Convenient sampling technique was used to select the students involved in both preliminary assessment stage and evaluation stage of the intended module. The minimum required students sample size for the preliminary assessment stage was 650 students after adding $10 \%$ for none responding, when the population size $=135458$ students who were registered the different faculties of Mansoura University. The desired precision= 4\%, Expected frequency of correct knowledge about healthy diet $=50 \%$, and design effect $=1$ in confidence limit of $95 \%{ }^{(14)}$. Proportion allocation technique was used to determine the sample size from each faculty.

Sixty-five students agreed to provide their feedback about the developed web site web. The professional experts group included ten academic staff members who had experience in health education, online education, and community health nursing. They were interviewed to obtain their opinions in relation to health education topic, web based teaching method, and required recommendations before designing the web based module. Their feedback was also obtained after the establishing the web-based module. This number of students and experts was enough to provide a feedback for content and face validity of the web- based nutritional health education module according to the Day J and Bobeva M (2005) who stated that useful results could be obtained from small size, homogeneous groups of 10-15 experts sampling ${ }^{(15)}$.

\subsection{Process of module development:}

The intended web- based nutritional health education module was developed based on evidence- based approach.

\subsubsection{Preliminary assessment stage:}

The preliminary assessment stage concerning about assessing students' nutritional needs. It included assessment of students' nutritional knowledge and their dietary practice. Students' nutritional health status was also assessed by determining their Body Mass index (BMI). During this stage, Researchers explored the students' preferences regarding the content of a nutritional health education module, preferred media, and web site based criteria. Moreover, it was important to figure out views of the professional experts regarding content, and suggested media of nutritional health education module.

Five tools were used in conducting the preliminary assessment. The first tool was "Students' sociodemographic self-administered structured questionnaire". Fahmi and El-Sherbeiny socioeconomic scale was adopted to assess students' socio-economic level. According to this scale the high social class scored from 2429 scores, middle social class scored from 18- 23 scores, low social class scored from 12- 17 scores and very low social class scored from 0 - 11 scores ${ }^{(16)}$. Students' demographic characteristics such as age, sex, academic year, faculty name, residency area were added as introductory part. The second tool was "Students' nutritional health measurement" Students' weight and height were measured to calculate their body mass index that was calculated by dividing body weight in kilograms by the square of height in meters $\left(\mathrm{kg} / \mathrm{m}^{2}\right)$. The Centers for Disease Control and Prevention cut -off points of BMI was used ${ }^{(17)}$. The third tool was "Students' nutritional knowledge self-administered structured questionnaire". This questionnaire was used to assess students' knowledge about healthy diet and its components, as well as function of nutrient, nutritional related diseases and nutritional facts label. The total scores is divided into three levels: poor level $=$ less than $50 \%$ of total scores, fair level $=50 \%$ to $65 \%$ of total scores, good level= more than $65 \%$ of total scores. The fourth tool was "Students' dietary practices self-administered structured questionnaire". This questionnaire was used to assess the student's dietary practices. The questionnaire was divided into four categories related to dietary pattern, food choices practices, foodstuff consumption practices, and food safety habits. Dietary practice was classified into satisfactory practice that equal $65 \%$ scores of the questionnaire total scores and unsatisfactory practice that equal less than $65 \%$ of the questionnaire total scores. The "total food frequency consumption method" was used as 
stated by ${ }^{(18,19)}$. The fifth tool was "Opinions of students and professional experts about criteria of health education structured self-administered questionnaire. This questionnaire was used to explore the students and professional experts' opinions in relation to the construction of the web- evidence based nutritional health module. The questionnaire concerned with the content of nutritional health education module, educational methods, media, and the general features of the web site.

\subsubsection{Development stage of the web- based nutritional health education module}

\subsubsection{Content development}

According to the results of the preliminary assessment, which indicated unsatisfactory dietary pattern among students, as well as the findings of the valid evidences, this web- based nutritional health education module was developed. Evidence- based practice approach was used in developing the current module.

\subsection{Developing Answerable Clinical Questions:}

The answerable searching questions were developed according to Glazioet al. $2007{ }^{(20)}$ in a PICOT framework (Patient, Intervention, Comparison, Outcome and Time) (Box 1). A number of keywords was used to answer the searching questions (Box 2).

\section{Box 1: Answerable searching questions}

1. What is the effect of student's university knowledge on adherence to healthy nutritional practices?
2. What are the major nutritional concerns of the university students?
3. What are the food choices motives that promote healthy eating of university students?
4. What are the nutritional requirements of university students?
5. Among university students, Dose healthy diet combined with physical exercise compared healthy diet only maintains normal
weight?
6. Dose health educations on food safety measures increase awareness of university students?
7. What is the main source of nutritional information that used by university students?
8. Is using web based teaching compared with traditional teaching effective in providing health education for university students?
9. What are the principles of effective web based teaching strategies?
10. What are the most appropriate design for web based nutritional health education module
11. What are the preferences of university students regarding multimedia that enhance learning?

\section{Box 2: The keywords that used to answer answerable search questions}

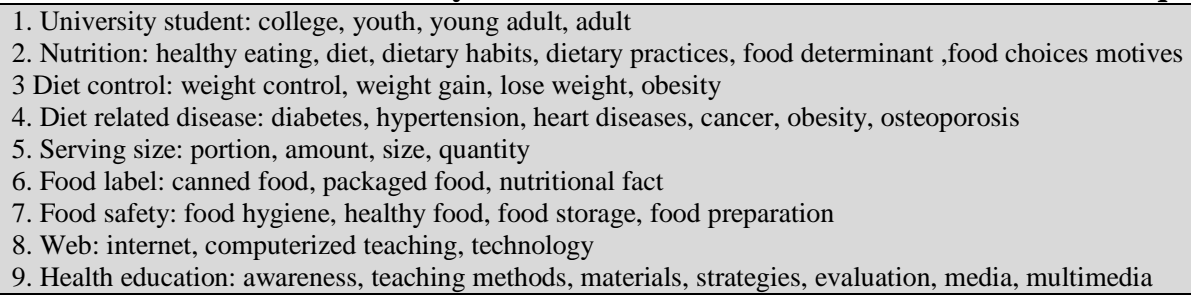

\subsection{Tracking down of evidences:}

Tracking down of evidence included published literatures in English language from the year 2005 up to 2016. A total number of 350 studies were tracked down from the electronic databases (Box 3). Out of these studies, a total number of 205 studies were valid and used in the development of health education module. The valid studies included 50 systematic reviews and meta-analysis, 9 randomized control trial, 10 cohort studies, 4 case control studies, and 22 cross sectional studies in addition to 120 guidelines.

\section{Box 3: The searched electronic bibliographic databases were:}

1. Center for Disease Control (www.cdc.gov)

2. Center for evidence-based nursing (http://www.york.ac.uk/healthscience/centres/evidence/cebn.htm)

3. Cochrane Database of Systematic Review (http://www.thecochranelibrary.com)

4. EBSCO (www.Ebscohost.com)

5. ERIC (http://eric.ed.gov)

6. Google scholar ( https://scholar.google.com.eg/)

7. National Guideline Clearing House (http://www.guidelines.gov)

8. Pub Med (http://www.pubmed.gov/entrez/query.fcgi)

9. Research Gate (https://www.researchgate.net)

10. Science Direct (http://www.sciencedirect.com/)

11. SIGN (http://www.show.scot.nhs.uk/sign/guidelines/index.html)

12. Springer (www.link.springer.com )

13. WileyOnlineLibrary (http://onlinelibrary.wiley.com/advanced/search)

14. World Health Organization (www.who.int)

15.Worldwide Science (http://worldwidescience.org) 


\subsection{Critical appraisal of evidence and grading recommendations}

The retrieved studies were appraised throughout three main steps namely; study validity rating, determination level of evidence and finally the grade of recommendation.

\subsection{Study Validity Rating: -}

All primary studies and reviews addressing the relevant topic were appraised by using the "SIGN checklist" (21) that appropriate to the study design, and then were individually rated for internal validity using the following system (Box 4).

Box 4: Rating of the internal validity description system for the tracked evidences according to the Scottish Intercollegiate Guideline Network (SIGN) System

\begin{tabular}{|c|l|}
\hline Rating & \multicolumn{1}{c|}{ Description } \\
\hline++ & All or most of the criteria have been fulfilled \\
\hline+ & Some of the criteria have been fulfilled \\
\hline- & Few or no criteria fulfilled \\
\hline
\end{tabular}

\subsection{Determination of evidence level:}

Determination of evidence level was determined by the "Generic Appraisal Tool for Epidemiology" ${ }^{(22)}$.The study design of each tracked evidence was assigned by numerical prefix and rating level of evidence using the system below (Box 5):

Box 5: Numerical prefix assigned to different study designs rating level of evidence according to the Generic Appraisal Tool for Epidemiology" (GATE 2001)

\begin{tabular}{|c|c|c|c|}
\hline Type of study design & $\begin{array}{l}\text { Grading level of } \\
\text { study numerical } \\
\text { prefix }\end{array}$ & $\begin{array}{l}\text { Rating } \\
\text { level of } \\
\text { evidence }\end{array}$ & Type of evidence \\
\hline \multirow{3}{*}{$\begin{array}{l}\text { Systematic review or meta- } \\
\text { analysis or randomized control } \\
\text { trials (RCTs). }\end{array}$} & \multirow{3}{*}{1} & $1++$ & $\begin{array}{l}\text { High quality meta-analysis, systematic reviews of randomized control } \\
\text { trails with a very low risk of bias. }\end{array}$ \\
\hline & & $1+$ & $\begin{array}{l}\text { Well conducted meta -analysis, systematic reviews or randomized } \\
\text { control trails with a low risk of bias. }\end{array}$ \\
\hline & & 1- & $\begin{array}{l}\text { Meta-analysis, systematic reviews or randomized control trails with a } \\
\text { high risk of bias. }\end{array}$ \\
\hline \multirow{3}{*}{$\begin{array}{l}\text { Cohort and case-control } \\
\text { studies }\end{array}$} & \multirow{3}{*}{2} & $2++$ & $\begin{array}{l}\text { High quality systemic reviews of case-control or cohort studies with a } \\
\text { very low risk of bias and a high probability that the relationship is } \\
\text { causal. }\end{array}$ \\
\hline & & $2+$ & $\begin{array}{l}\text { Well conducted case-control or cohort studies with a low risk of bias } \\
\text { and a moderate probability that the relationship is causal. }\end{array}$ \\
\hline & & 2- & $\begin{array}{l}\text { Case-control or cohort studies with a high risk of bias and a significant } \\
\text { risk that the relationship is not causal. }\end{array}$ \\
\hline Case report series. & 3 & 3 & Non-analytic studies, e.g. case reports and case series. \\
\hline $\begin{array}{l}\text { Expert's opinion/logical } \\
\text { argument/common sense }\end{array}$ & 4 & 4 & Expert opinion \\
\hline
\end{tabular}

\subsection{Grading of Recommendations}

The detailed results of each study were considered in the formulation of each health education module recommendations that were then graded using the system of the "Scottish Intercollegiate Guideline Network" (www.sign.ac.uk) ${ }^{(21)},($ Box 6$)$

Box 6: Grading system of recommendations used in developing the web- based nutritional health education module according to the Scottish Intercollegiate Guideline Network (SIGN) System

\begin{tabular}{|c|c|}
\hline Grade & Recommendation \\
\hline $\mathbf{A}$ & $\begin{array}{l}\text { At least one meta-analysis, systematic review, or RCT rated as } 1++ \text {. And directly applicable to the target population, or a body } \\
\text { of evidence consisting principally of studies rated as } 1+\text {, directly applicable to the target population and demonstrating overall } \\
\text { consistency of results. }\end{array}$ \\
\hline B & $\begin{array}{l}\text { A body of evidence including studies rated as } 2++ \text {, directly applicable to the target population and demonstrating overall } \\
\text { consistency of result, or extrapolated evidence from studies rated as } 1++ \text { or } 1+\text {. }\end{array}$ \\
\hline C & $\begin{array}{l}\text { A body of evidence including studies rated as } 2+\text {, directly applicable to the target population and demonstrating overall } \\
\text { consistency of result, or extrapolated evidence from studies rated as } 2++ \text {. }\end{array}$ \\
\hline D & Evidence level 3 or 4 , or extrapolated evidence from studies rated as $2+$. \\
\hline
\end{tabular}

\subsubsection{Formulation of web - based nutritional health education module}

A framework was developed based on the evidence-based recommendations related to components of web- based nutritional health education module was drawn up.

\subsubsection{Website development}

The web site was developed by using set of technical and instructional standards which developed by web designer team. The researchers with the web designer selected a learning platform. A learning platform is a set of interactive online services that provide learners with access to information, tools, and resources to support educational delivery and management through the Internet. 


\subsubsection{Dissemination stage}

The content of the designed module were uploaded to the web site. The web site marketing was done through posting a face- book posts during the period from 21 to 30 June 2016.

\subsubsection{Evaluation of module's internal validation stage:}

Web- based health education module was evaluated for its internal validation by obtaining the experts and students feedback. The link of the site (www.Thehealthgardens.com) was distributed to 10 experts and 65 university students to test the content and face validity of the module. Any specific instructions and comments from experts' evaluation were documented and considered in the module formulation. A checklist of "Expert and students feedback checklist" was developed by the researchers to test the internal validity of the health education module. This checklist explored experts and students' feedback about the developed web based nutrition module. The feedback checklist concerned with the content, design, educational strategies, accessibility of the web site, language used, and quality of media.

\subsection{Official, ethical, and other technical issues:}

\subsubsection{Approval and permissions}

The approval of community health nursing department was obtained. An official letter from undergraduate affairs Faculty of Nursing was submitted to all faculties affiliated to Mansoura University to obtain their approval to conduct the study.

\subsubsection{Informed consent:}

Approval of the research ethics committee of the Faculty of Nursing, Mansoura University was obtained. A written informed consent was obtained from the students to participate in the study after explanation of the study purpose.

\subsubsection{Validity testing of the developed tools:}

The content and face validity of all study tools that were developed by the research was tested. A jury group of five experts of community health nursing tested the content validity of the developed tools. In addition to a pilot study that was conducted on $10 \%$ of study subjects (65 students). Those students were selected randomly from different faculties and they were not included in the study. The pilot study aimed at evaluation of the clarity and applicability of the research tools. As well as the pilot study used to estimate the approximate time required for data collection, and to identify the possible obstacles that may hinder data collection. Based on the collected information, the necessary modifications were done.

\subsection{Data Analysis}

Data were analyzed by using SPSS (Stand for Statistical Productive and Service Solution) version 20.0. Descriptive statistics in the form of frequencies for nominal and categorical variables and arithmetic mean \pm standard deviation for continuous variables.

\subsection{Preliminary assessment}

\section{Results}

Table (1) shows that $57.8 \%$ of students were female and $73.2 \%$ of them were aged less than 20 years. Regarding residence area, $55.8 \%$ of students lived in rural area and $88.2 \%$ of them lived at their family home. Table reveals that $48.9 \%$ of students belonged to middle social class, and $34.3 \%$ belonged to high social class. While only $13.2 \%$ and $3.5 \%$ of the students belonged to low and very low social class respectively.

Table (1): Distribution of students according to their socio demographic characteristics

\begin{tabular}{|c|c|c|}
\hline Items & $\begin{array}{c}\text { Frequency } \\
N=650\end{array}$ & $\begin{array}{c}\text { Percent } \\
\% \\
\end{array}$ \\
\hline \multicolumn{3}{|l|}{ Gender } \\
\hline Male & 274 & 42.2 \\
\hline Female & 376 & 57.8 \\
\hline \multicolumn{3}{|l|}{ Age } \\
\hline$\geq 20$ Years & 476 & 73.2 \\
\hline$\leq 20$ years & 174 & 26.8 \\
\hline$\overline{\mathrm{X}} \pm$ SD & \multicolumn{2}{|c|}{$20.1 \pm 1.2$} \\
\hline \multicolumn{3}{|l|}{ Current residence area } \\
\hline Family home & 573 & 88.2 \\
\hline House of emigrants & 21 & 3.2 \\
\hline College town & 56 & 8.6 \\
\hline \multicolumn{3}{|l|}{ Permanent residence area } \\
\hline Urban & 287 & 44.2 \\
\hline Rural & 363 & 55.8 \\
\hline \multicolumn{3}{|l|}{ Social class } \\
\hline High social class & 223 & 34.3 \\
\hline Middle social class & 318 & 48.9 \\
\hline Low social class & 86 & 13.2 \\
\hline Very low social class & 23 & 3.5 \\
\hline$\overline{\mathrm{X}} \pm \mathrm{SD}$ & \multicolumn{2}{|c|}{$18.95 \pm 0.77$} \\
\hline
\end{tabular}


Table (2) reveals that $94 \%$ of students had poor knowledge level about healthy diet and its components

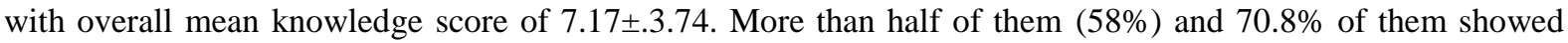
poor knowledge level related to their functions of nutrients and nutrition related diseases, respectively.

Table (2): Distribution of students according to their level of knowledge regarding to healthy diet and its component

\begin{tabular}{|c|c|c|c|c|c|c|c|}
\hline \multirow{3}{*}{ Items } & \multirow{3}{*}{$\bar{X} \pm$ SD } & \multicolumn{6}{|c|}{ Score level $N=650$} \\
\hline & & \multicolumn{2}{|c|}{$\begin{array}{l}\text { Poor } \\
<50 \%\end{array}$} & \multicolumn{2}{|c|}{$\begin{array}{c}\text { Fair } \\
50-<65 \%\end{array}$} & \multicolumn{2}{|c|}{$\begin{array}{l}\text { Good } \\
\geq 65 \%\end{array}$} \\
\hline & & $\mathbf{N}$ & $\%$ & $\mathbf{N}$ & $\%$ & $\mathbf{N}$ & $\%$ \\
\hline Healthy diet and its components $($ Score $=28)$ & $7.17 \pm .3 .74$ & 611 & 94 & 30 & 4.7 & 9 & 1.4 \\
\hline Functions of nutrients $($ Score $=10)$ & $3.85 \pm .2 .12$ & 377 & 58 & 164 & 25.2 & 109 & 16.8 \\
\hline Nutrition related diseases $($ Score $=11)$ & $4.08 \pm .2 .41$ & 460 & 70.8 & 133 & 20.5 & 57 & 8.8 \\
\hline Nutrition facts label $($ Score $=1)$ & $0.02 \pm 0.14$ & 637 & 98 & 0.0 & 0.0 & 13 & 2 \\
\hline Overall knowledge scores $($ Score $=50)$ & $16.77 \pm 7.56$ & 546 & 84 & 80 & 12.3 & 24 & 3.7 \\
\hline
\end{tabular}

Table (3) illustrates that the university students consumed mean serving of foodstuff less than the ideal serving by at least $-30 \%$ for fruits up to $-81 \%$ for beans and legume. They consume other foodstuff and beverage much higher than the recommended ideal serving such as sweets, soft drinks as well as tea and coffee.

Table (3): Distribution of study group according to their daily consumption of food and beverages

\begin{tabular}{|l|c|c|}
\hline \multicolumn{1}{|c|}{$\begin{array}{c}\text { Ideal serving*/week of foodstuff and } \\
\text { beverages }\end{array}$} & $\begin{array}{c}\text { Consumed serving of foodstuff } \\
\text { and beverages / week } \\
\overline{\mathbf{X}} \pm \text { SD }\end{array}$ & $\begin{array}{c}\text { \% of difference between } \\
\text { consumed and ideal serving of } \\
\text { foodstuff and beverages }\end{array}$ \\
\hline Fruits (14-28) & $9.8 \pm 6.7$ & $-30 \%$ \\
\hline Vegetables (21-35) & $6.8 \pm 5.7$ & $-67.6 \%$ \\
\hline Bread and cereals (42-56) & $12.3 \pm 7.3$ & $-70.7 \%$ \\
\hline Milk and milk products (14-21) & $6.2 \pm 6.3$ & $-55.7 \%$ \\
\hline Sweets (0) & $6.5 \pm 6.8$ & $650 \%$ \\
\hline Tea and coffee (2) & $6.9 \pm 8.5$ & $245 \%$ \\
\hline Fresh juices (3-5) & $6.6 \pm 6.4$ & $120 \%$ \\
\hline Soft drinks (0) & $6.8 \pm 7.1$ & $680 \%$ \\
\hline Meat and Poultry (2-3) & $2.3 \pm 7.7$ & $15 \%$ \\
\hline Fish (2-3) & $1.4 \pm 7.7$ & $-30 \%$ \\
\hline Beans and Legume (6-8) & $1.1 \pm 6.2$ & $-81.6 \%$ \\
\hline
\end{tabular}

"Serving: is a standard measured amount that used to help give advice about how much to eat or to identify how many calories and nutrients are in a food ${ }^{(23)}$

$\%$ of difference calculated from the minimum ideal serving/ week

Table (4) displays that $78.5 \%$ of students showed unsatisfactory dietary pattern. The most of them (99.2\%) exhibited unsatisfactory eating and food choice habits. On other hand, $83.7 \%$ of students exhibited satisfactory food safety practices. Generally, $98.6 \%$ of them showed unsatisfactory dietary practices.

Table (4): Distribution of student's according to their satisfactory level of dietary practices

\begin{tabular}{|c|c|c|c|c|c|}
\hline \multirow{3}{*}{ Items } & \multirow{3}{*}{$\bar{X} \pm$ SD } & \multicolumn{4}{|c|}{ Score level $\mathbf{N}=\mathbf{6 5 0}$} \\
\hline & & \multicolumn{2}{|c|}{ Unsatisfactory $<65 \%$} & \multicolumn{2}{|c|}{ Satisfactory $\geq 65 \%$} \\
\hline & & $\mathbf{N}$ & $\%$ & $\mathbf{N}$ & $\%$ \\
\hline Dietary pattern $($ Scores $=57)$ & $31.59 \pm 4.6$ & 510 & 78.5 & 140 & 21.5 \\
\hline Eating and food choice habits (Scores $=158$ ) & $73.23 \pm 11.8$ & 645 & 99.2 & 5 & .8 \\
\hline Food safety practice $($ Scores $=18)$ & $14.80 \pm 3$ & 106 & 16.3 & 544 & 83.7 \\
\hline Total practice score $($ Scores $=233)$ & $131.46 \pm .14 .4$ & 641 & 98.6 & 9 & 1.4 \\
\hline
\end{tabular}

Table (5) reveals that $34.3 \%$ of the students were overweight and only $7.4 \%$ of them were obese. Results show insignificant difference between body mass index categories and gender, although the overweight and obesity were higher among females than males.

Table (5): Distribution of students according to their gender in relation to body mass index

\begin{tabular}{|c|c|c|c|c|c|c|c|c|}
\hline \multirow{3}{*}{ BMI categories } & \multirow{2}{*}{\multicolumn{2}{|c|}{$\begin{array}{c}\text { Total } \\
\text { number } \\
\mathrm{N}=650\end{array}$}} & \multicolumn{6}{|c|}{ Gender } \\
\hline & & & \multicolumn{2}{|c|}{$\begin{array}{c}\text { Male } \\
\mathrm{N}=274\end{array}$} & \multicolumn{2}{|c|}{$\begin{array}{l}\text { Female } \\
N=376\end{array}$} & \multirow{2}{*}{$\chi^{2}$} & \multirow{2}{*}{$\mathbf{P}$} \\
\hline & $\mathbf{N}$ & $\%$ & $\mathbf{N}$ & $\%$ & $\mathbf{N}$ & $\%$ & & \\
\hline Under weight & 17 & 2.6 & 4 & 1.5 & 13 & 3.5 & \multirow{5}{*}{7.16} & \multirow{5}{*}{0.12} \\
\hline Normal weight & 362 & 55.7 & $\begin{array}{c}16 \\
7\end{array}$ & 60.9 & 195 & 51.8 & & \\
\hline Over weight & 223 & 34.3 & 83 & 30.3 & 140 & 37.3 & & \\
\hline $\begin{array}{l}\text { Mild obesity } \\
\text { (obesity grade I) }\end{array}$ & 37 & 5.7 & 16 & 5.8 & 21 & 5.6 & & \\
\hline Moderate obesity(obese grade II) & 11 & 1.7 & 4 & 1.5 & 7 & 1.8 & & \\
\hline Body mass index $(\bar{X} \pm S D)$ & \multicolumn{8}{|c|}{$24.57 \pm 3.99$} \\
\hline
\end{tabular}


Box (7) reveals that all students recommended content topics of the module. The content was approved to include general information concerning healthy diet, weight maintenance, and information related to nutrition related disease. All of them mentioned that, the module should contain topics of preventive nutrition and food safety issues. Regarding preferred media, all students mentioned using of audiovisual such as video that grasp attention and confirm the health education massages combined with text. All experts recommended the same media types plus using of graphics and animation. In relation to website design criteria, all students preferred that website should be easy to open at any time, easy to navigate, contain concise and update information, and the learning material can be download. Experts add that web site would include feedback and evaluation tools.

\section{Box (7): Criteria of nutritional health education web based module as mentioned by university students} and experts

\begin{tabular}{|c|l|l|}
\hline $\begin{array}{c}\text { Criteria of nutritional health } \\
\text { education web based module }\end{array}$ & \multicolumn{1}{|c|}{ University students' preference } & \multicolumn{1}{c|}{ Experts' opinions } \\
\hline \multirow{2}{*}{ Module contents } & $\begin{array}{l}\text { Healthy diet } \\
\text { Weight maintenance } \\
\text { Related to nutritional related diseases }\end{array}$ & $\begin{array}{l}\text { Basic concept of nutrition } \\
\text { Components of healthy diets } \\
\text { Nutritional label and purchasing healthy } \\
\text { packaged food } \\
\text { Weight maintenance } \\
\text { Food safety } \\
\text { Diet related diseases }\end{array}$ \\
\hline Media & & $\begin{array}{l}\text { Audiovisual } \\
\text { Picture and graphic with animation }\end{array}$ \\
\hline \multirow{2}{*}{ Website design criteria } & $\begin{array}{l}\text { Audio visual } \\
\text { Picture and text }\end{array}$ & $\begin{array}{l}\text { Easy to navigate } \\
\text { Easy to open at any time } \\
\text { Open at any time and any were } \\
\text { Contain comments and feedback icons } \\
\text { Contain concise information } \\
\text { Contain tutorial icon } \\
\text { Content can be downloaded }\end{array}$ \\
\hline
\end{tabular}

\subsection{Description of the developed web - based nutrition health education module}

Box (8) presents the evidence- based linked components of the nutritional health education module. The module composed of two main items; content and instructional strategies that were stated based on evidencebased approach.

\subsubsection{Module Content:}

Component of healthy diet should include macronutrients and micronutrient. This recommendation was based on twenty cross sectional studies(graded level 2++), and five systematic review of strong design (graded level 1++),five expert opinion (graded level 4) and 17 guideline (graded level 4), (Component number 1.1 Box 8).The component of healthy diet would follow the eating plate model. This model determined a specified amount of all nutrients should be included in each eating plate. This conclusion based on of two expert opinions (graded level 4) and five guidelines (graded level 4), (Component number 1.2 Box 8).

The daily-required amount of foodstuff and beverage serving should focus in health education. According to four expert opinions (graded level 4) and twenty guidelines (graded level 4), the amount of serving is expressed as the size and number of each nutrient that foodstuff included (Component number 1.3 Box 8).

Combination of physical activity with dietary regimen is essential element for maintaining healthy weight was highly recommended in two systematic reviews (graded level 1+), two systematic reviews (graded level $2++$ ), and ten guidelines (graded level 4). In addition, the amount of daily physical activities should be mentioned in nutritional health education module (Component number 1.4 and 1.5 Box 8).

Based on three expert opinion (graded level 4), two randomized control trails (RCTs) (graded level 1+), and five guidelines (graded level 4), it was recommended that health education should provide information about the characteristics of packaged food and the importance of reading food label. These are crucial issues in selecting healthy food (Component number 1.6 and 1.7 Box 8).

Safety food and healthy way of cooking are important issues that reduce food borne diseases based on two systematic review (graded level 2++), three expert opinions and two guidelines (graded level 4). Therefore, these issues should be included in health education according to two expert opinion (graded level 4) and five guidelines (graded level 4), (Component number 1.8 Box 8).

\subsubsection{Instructional strategies:}

Based on evidence there are instructional strategies, which should be followed in establishing web- based health education module. It is essential to consider the criteria of effective web based design. These criteria include easy navigation, simple structure with help icons, and possibility to assimilate different types of multimedia. These criteria were recommended on the basis of one systematic review (graded level 1+), one systematic review (graded level 2++), three experts opinion (graded level 4) and three guidelines (graded level 4), (Component number 2.1 Box 8).Scientific content of the module should be delivered in simplified focused health education massages. This strategy was Based on one guideline (graded level 4), and one expert opinion (graded level 4) (Component number 2.2 Box 8). 
To achieve the goal of effective web- based health education, it is important to use effective teaching and learning methods. It was concluded that using appropriate health educational strategy and different multimedia would attract the learners' attention. Accordingly, promotion in their learning process would be achieved. This instructions were synthesized on the basis of five systematic reviews (graded level 1++), three systematic reviews (graded level 1+), one systematic reviews (graded level 2++), twenty cross sectional studies (graded level 2++), and four RCTs (graded level 1), (Component number 2.3 Box 8).

Other important issue is the evaluation of the achieved learning outcomes; the web- based health education module should include appropriate evaluation strategy for measuring the achieved learning outcomes through posttest and feedback. This was recommended according to one systematic review (graded level 1+), two RCTs (graded level 1+), four experts opinions (graded level 4), three guidelines (graded level 4), (Component number 2.4 Box 8).

Box 8: Evidence- linked components of web based nutritional health education module

\begin{tabular}{clc}
\hline Ser. & Module Content & Grade \\
\hline 1. & Components & A, D \\
\hline 1.1 & Component of healthy diet include macronutrients and micronutrient & D \\
1.2 & Healthy eating plate & D \\
1.3 & Serving from different nutrient & A, B, C, D \\
1.4 & Maintenance of healthy weight & A, D \\
1.5 & Physical activity & B, D \\
1.6 & Healthy packaged food & B, D \\
1.7 & Food Label & A, D \\
\hline 1.8 & Food safety and healthy cooking technique & B, C, D \\
\hline 2 & Instructional strategies & D \\
\hline 2.1 & Apply the criteria of effective web based design & A, B, C, D \\
2.3 & Simplify the scientific content that are focused on the criteria of effective health education & A, D \\
\hline
\end{tabular}

Box (9) displays the components of web evidence -based nutritional health education module. It was written in Arabic language and English. It was started with a brief introduction about the burdens of unhealthy diet and benefits of providing this information. The general goal of the module aimed at promoting the individuals' health and wellbeing of young adult. The content was arranged at five lessons, which included 21 health messages. Audiovisual media in forms of pictures, graphic, and video were used to support these messages. The web- based nutritional health education module was uploaded on web site "www.Thehealthgardens.com".

Box (9): Description of web evidence based nutritional health educational module

\begin{tabular}{|c|c|}
\hline Components & Description \\
\hline Language & Arabic version and English \\
\hline Introduction & $\begin{array}{l}\text { Highlight on: } \\
\text { - Burden of unhealthy diet } \\
\text { - Benefits of increasing nutritional awareness }\end{array}$ \\
\hline Intended users & Healthy young adults \\
\hline Scope & Preventive nutrition \\
\hline Goal & To promote the individuals' health and wellbeing \\
\hline Specific objectives & $\begin{array}{l}\text { - To enable university students to select healthy food } \\
\text { - To enable university students to calculate their daily calories intake }\end{array}$ \\
\hline \multicolumn{2}{|r|}{ (2: } \\
\hline $\begin{array}{l}\text { Lesson one: component of } \\
\text { healthy diet and its importance }\end{array}$ & $\begin{array}{l}\text { Massage 1: Definitions of healthy diet } \\
\text { Massage 2: Component of the healthy diet } \\
\text { Massage 3: Importance of nutrients } \\
\text { Massage 4: Sources of the nutrients } \\
\text { Massage 5: Daily required amount of nutrients }\end{array}$ \\
\hline $\begin{array}{l}\text { Lesson two: } \\
\text { Healthy eating plate }\end{array}$ & $\begin{array}{l}\text { Massage 1: Healthy eating plate } \\
\text { Massage 2: Vegetables } \\
\text { Massage 3: Fruits } \\
\text { Massage 4: Whole grains } \\
\text { Massage 5: Proteins } \\
\text { Massage 6: Types of fat } \\
\text { Massage 7: Waters }\end{array}$ \\
\hline $\begin{array}{l}\text { Lesson three: } \\
\text { Packaged food and food label }\end{array}$ & $\begin{array}{l}\text { Massage 1: Characteristics of healthy packaged food } \\
\text { Massage 2: Food label }\end{array}$ \\
\hline $\begin{array}{l}\text { lesson four: } \\
\text { weight maintenance }\end{array}$ & $\begin{array}{l}\text { Massage 1: Body mass index } \\
\text { Massage 2: Keep the healthy weight } \\
\text { Massage 3: Physical activity }\end{array}$ \\
\hline Lesson five: & Massage 1: Consideration when buying, handling, and storing packaged foods \\
\hline
\end{tabular}




\begin{tabular}{|l|l|}
\hline Food safety & $\begin{array}{l}\text { Massage 2: Healthy cooking techniques } \\
\text { Massage 3: Best Choices for cooking oils } \\
\text { Massage 4: General food safety practices }\end{array}$ \\
\hline
\end{tabular}

\subsection{Testing internal validity of the developed web based module}

The content validity of the developed web based module was evaluated by experts and target population themselves (university students). Diagram (1) reveals that all experts found the topic of educational web based module is important and significant for the target group. All experts mentioned that the objectives were clear and written according to Bloom's taxonomy. They approved that the content is adequate and updated to achieve the intended objectives and appropriate to the level of understanding. Production of the module in Arabic and English languages would facilitate approaching the target group. They described the illustrations manner to be simple, related to content, and integrated with text. All experts found the used media was clear, attractive, appropriate to the content, and clarify the health massages. Regarding the general design of the web site, all experts mentioned that the web site design followed the principles of web design and facilitated navigation. All experts mentioned that the format of web pages was appropriate in size, style of letters as well as the spacing and length of lines. Using of bold characters and bullet points draw attention to the key content.

\section{Diagram (1): Distribution of experts' evaluation regarding to web evidence based nutritional education design}

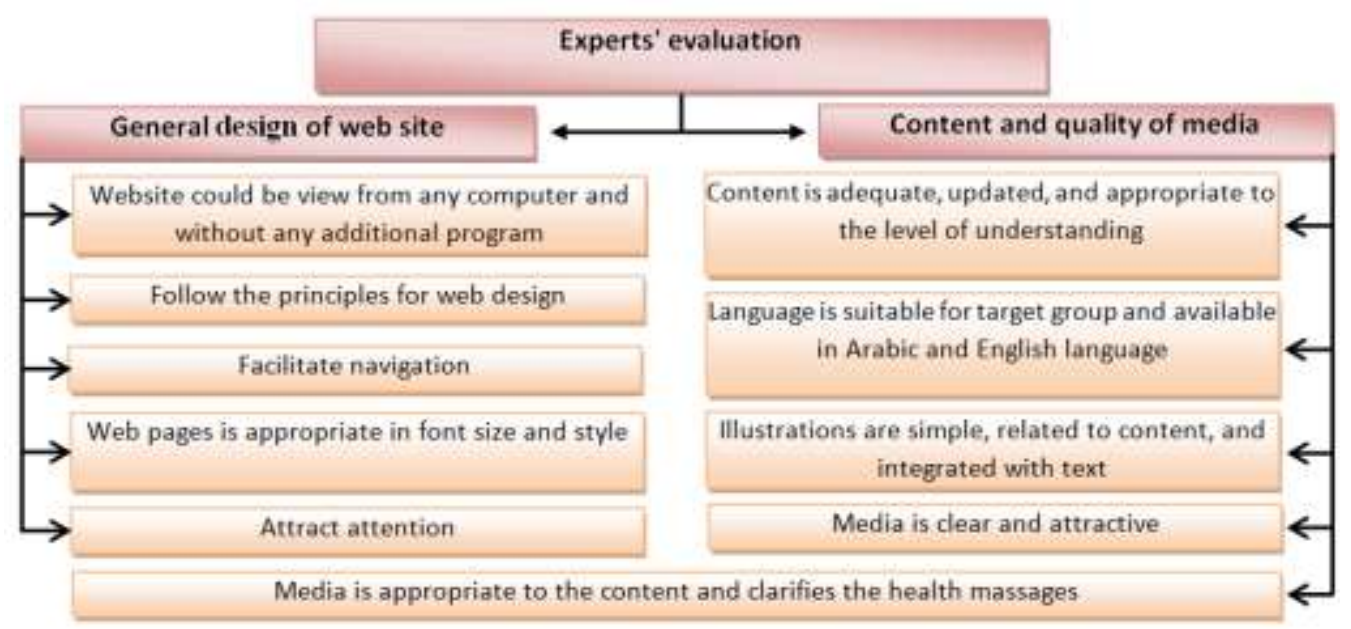

Diagram (2) shows that all students found the general design of the web site, was beneficial, and covered the intended objectives. The majority of students $(88.3 \%$ and $86.7 \%)$ found the electronic materials would promote learning and would help in solving their dietary problems, respectively. On other hand, only $13.3 \%$ of them had obstacles during using the web site. Regarding the browsing technique, all students mentioned that the browsing technique is suitable and constant. They found the presentation of content was attractive, and the used terminologies were clear. All of them mentioned that the used media achieve the intended objectives, video was clear; and background did not distract attention.

\section{Diagram (2): Distribution of student's' feedback about the design web based nutritional health educational module} Students' feedback about developed web based module

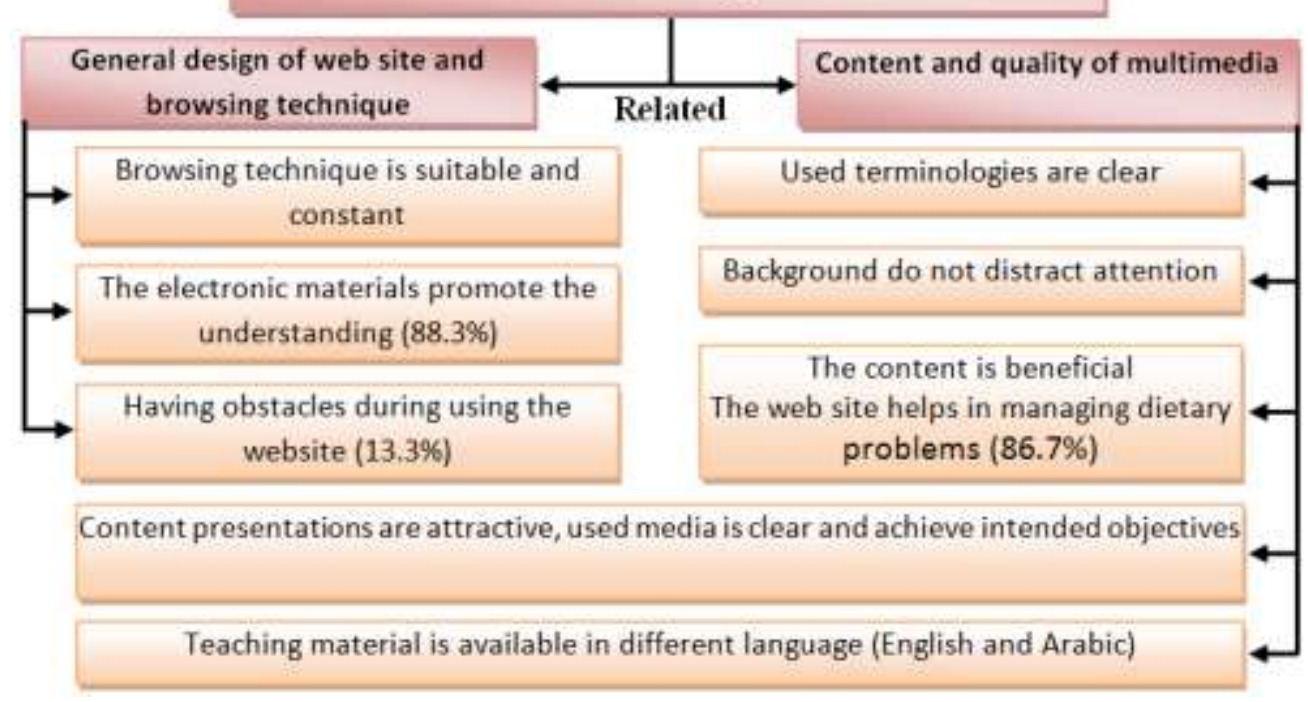




\section{Discussion}

Healthy nutrition is a fundamental key to a better quality of life. The years spent at the university represent a critical period of individuals' health. Individuals may practice unhealthy changes in eating behavior during university time. These changes negatively influence their quality of lifestyle including eating habits ${ }^{(24,25)}$. Therefore, this study aimed at developing a web- based nutritional health education module that might improve healthy eating behaviors among university students. Prior to the development of this module, nutritional knowledge and dietary pattern indices of university students were explored.

Nutritional knowledge is important issue because it influences healthy food choices and dietary pattern. However, socio- economic, cultural, and food availability are factors that limit translating knowledge into practice. University students may choose cheap and convenient foods that are easily available regardless of their nutritional values ${ }^{(26)}$. The present study showed poor knowledge level among most of studied university student in relation to the healthy diet and its components. They showed poor knowledge level regarding to the importance of nutritional label as well as nutrition related diseases. These findings were in agreement with several studies, which indicated a lack of knowledge in all nutritional aspects ${ }^{(26,27)}$. The reported poor knowledge level of the current studied university students was reflected on their food choices and dietary pattern. Dietary pattern is viewed as food habits that include the types of food eaten as well as number and time of meals intake. Dietary patterns reflect the types of foods and their nutrient content taken by individuals or groups of people ${ }^{(28)}$. According to the WHO, the recommended intake of fruits and vegetables is 400 gram per day that equal 5 serving/ day ${ }^{(29)}$. The present study was in agreement with Al-Rethaiaa et al, (2010) ${ }^{(30)}$, who reported that university students used to consume low daily intake of fruits and vegetables. Regarding to milk and milk products the "American Dietary Guidelines, 2015" ${ }^{(31)}$ reported that the consumption of that stuff must be two to three serving per day. The present study found that university students reported low consumption of milk and milk products. This finding was in agreement with Poddar et al, (2009) ${ }^{(32)}$ study, who found that the total amount of dairy consumed by students was approximately 1.5 servings per day. The present study revealed law fish intake as same as the findings of Milosavljević et al, $2015^{(33)}$ who reported low intake of fish among university students.

However, the poor dietary pattern was also reflected by the reported high intake of tea, coffee, and beverage among university students of this study. These findings were consistent with Milosavljević et al, 2015 ${ }^{(33)}$ who found that university students used to consume high amount of soft drinks. In general, the current study showed unsatisfactory dietary pattern among more than three quadrants of university students and unsatisfactory food choice habits among the majority of them. These finding could be interpreted on the highlights of the findings of many authors, who reported that choice of food is related to the individual's level of nutritional knowledge and their awareness about nutrition related diseases ${ }^{(26,27,34, \text { and } 35)}$.

Lack of nutritional knowledge and poor dietary pattern were reflected on the health status of the studied university students. Overweight and obesity were observed among 34.3\% and 7.4\% of the studied university students respectively. These findings were similar to a study that was conducted in Lebanon by by Yahia et al, $20088^{(36)}$. Overweight and obesity were higher in female than male, this finding consistent with other study of ${ }^{(37)}$. The observed total BMI mean in the current study was consistent with study conducted in Saudi Arabia ${ }^{(30)}$ in which the mean of BMI was laid within the overweight category.

Unhealthy lifestyle behaviors such as dietary habits are modifiable and usually established during youth or young adulthood ${ }^{(38)}$. These dietary habits need to be promoted by providing health education information ${ }^{(39)}$. According to the results of the current study and reviewed literatures university students are active group in finding the necessary nutritional information by searching the internet ${ }^{(40,41 \text {, and } 42)}$. However not all social media and internet sources could be considered valid sources of nutritional information. So that the current web- based nutritional health education module was developed. For this aim, it was important to explore the opinions of health education experts and the end beneficiaries (university students) in relation to the best design of the module.

The current study revealed that both university students and health education experts emphasized on using of multimedia in web-based module would facilitate learning. They also agreed on the importance of simplicity of the web-based module in relation to navigation, content, and instruction icons. These findings were consistent with Kartam and AL-Reshaid ${ }^{(43)}$ who mentioned that any website should include multimedia and necessary education materials to promote the learning process.

Based on the conducted preliminary assessment and the valid available literatures the current webbased nutritional health education module was designed. The elements of the web- based module were identified and the overall course goal translated into more specific learning objectives for each unit. According to the revised Bloom's taxonomy, the learning objectives were developed to include the appropriate cognitive domains ${ }^{(44,45)}$. Since students vary in their learning styles, different instructional methods were used throughout the module. The taken approach in designing the present module go along with several studies which indicated that using of different illustrations forms is more effective in achieving the learning goals ${ }^{(43,46 \text { and } 47)}$. 
Kartam and AL-Reshaid ${ }^{(43)}$ and Singh ${ }^{(47)}$ stated that the end product of a web course should tested for technical functionality on the website and simplicity of use to students. Whenever the system failed to carry out any of its functions, it was taken back to the design stage for further technical reviews and modifications. This is consistent with the present study in which the content validity of the current web site was tested by experts and students. Likewise, other developed web- based modules the current one was revised for the used media, navigation, accessibility, and learning strategies. Experts and students found the developed web- based nutritional health education module was accessible, illustrated information clearly with attractive multimedia. These findings were similar to the results of several researchers whose modules were described to have effective text combined with graphs and multimedia-based educational content ${ }^{(43,46}$ and 47$)$. Finally nutrition health education that targeted university students, focused on improving dietary patterns by increasing knowledge on food value to promote the nutritional status of students.

\section{Conclusion and Recommendations}

The study concluded that university students required valid information about healthy nutrition that increase their nutritional awareness and consequently promote their health status. They preferred to receive this information via internet in attractive presentation. The develop web based nutritional health education module focused on measures that encourage students to form a good quality dietary practice. University students and health education experts accepted the current module. They were satisfied with the module content and the illustration methods. It was recommended to disseminate the current web- based nutritional health education module to university students. Further study to be conducted to evaluate the impact of disseminating this module on dietary practice of university students.

\section{Reference}

[1] Nelson MC, Story M, Larson NI, Neumark-Sztainer D, Lytle LA: Emerging adulthood and college-aged youth: An overlooked age for weight-related behavior change. Obes 2008,16(10):2205-2211.

[2] Lee, S. (2010). Eating Behaviors and Characteristics of Healthy Foods as Perceived by College Students. Retrieved from http://repositories.tdl.org/ttu-ir/bitstream/handle/2346/ETD-TTU-2010-12-1204/LEETHESIS.pdf?sequence $=2$

[3] Best College Review, (2012). COLLEGE GUIDES Health and Nutrition For College Students. [online] Available at: http://www.bestcollegereviews.org [Accessed 15 May 2017].

[4] World Health Organization. (2016). 5 keys to a healthy diet. [online] Available at: http://www.who.int/nutrition/topics/5keys_healthydiet/en/ [Accessed 15 May 2017].

[5] The National Heart, Lung, and Blood Institute. (2014). Overweight and Obesity. [online] Available at: https://www.ncbi.nlm.nih.gov/pubmedhealth/PMH0063069/ [Accessed 15 May 2017].

[6] McKinney, C. (2013). Assessment of Dietary Behaviors of College Students Participating in the Health Promotion Program BUCS: Live Well. ProQuest Dissertations and Theses, 99. https://doi.org/10.1016/j.jand.2013.06.258

[7] USDA Food Pyramid Out: Is The New Food Plate Better?. (2011). [online] Available at: http://2016 The HuffingtonPost.com, Inc. [Accessed 14 May 2017].

[8] Quagliani, D., \& Hermann, M. (2012). Practice Paper of the Academy of Nutrition and Dietetics Abstract: Communicating Accurate Food and Nutrition Information. Journal of the Academy of Nutrition and Dietetics, 112(5), 759. https://doi.org/10.1016/j.jand.2012.03.006

[9] Hsiao, H. (2010). Web-based Collaborative learning in secondary education : Teachers reflection. International Journal of Cyber Society and Education, 3(1), 15-36. Retrieved from http://academicpub.org/ojs/index.php/IJCSE/article/view/849

[10] Lin, S., \&Overbaugh, R. C. (2013). Autonomy of participation and ICT literacy in a self-directed learning environment (SDLE). Quality and Quantity, 47(1), 97-109. https://doi.org/10.1007/s 11135-011-9505-2

[11] Williams, G. C., Lynch, M., \& Glasgow, R. E. (2007). Computer-assisted intervention improves patientcentered diabetes care by increasing autonomy support. Health Psychology, 26(6), 728-734. https://doi.org/10.1037/0278-6133.26.6.728

[12] Clark, M. (2014). community health nursing :Advocacy for population health. 5th ed. United State of America: pearson Education, pp.14-16.

[13] Ross C. Brownson, Jonathan E. Fielding, and Christopher M. Maylahn. Evidence-based Decision Making to Improve Public Health Practice. Front Public Health Serv Syst Res 2013; 2(2).

[14] Schaeffer RL, Mendenhall W, Ott L. Elementary Survey Sampling, Fourth Edition. Duxbury Press, Belmont, California 1990

[15] Day J and Bobeva M., (2005). A Generic Toolkit for the Successful Management of Delphi Studies. The Electronic

Journal of Business Research Methodology 3 2, pp 103- 116. www.ejbrm.com 
[16] Fahmy S , El Sherbeiny A., 1983. Determining simple parameters for social classification for health research . bulletin of high institute of public health;13(5) : 95-107

[17] Centers for Disease Control and Prevention. Assessing Your Weight | Healthy Weight | CDC. (2015). Retrieved May 6, 2017, from https://www.cdc.gov/healthyweight/assessing/index.html

[18] Papadaki A, Scott JA. The impact on eating habits of temporary translocation from a Mediterranean to a Northern European environment. Eur J ClinNutr 2002;56(5):455

[19] Bagordo F, Grassi T, Serio F, Idolo A, De Donno A. Dietary habits and health among university students living at or away from home in southern Italy. Jo Food Nutr Res 2013;52(3):164-71.appet.2012.03.003

[20] Davies, K. S. (2011). Formulating the evidence based practice question: A review of the frameworks. Evidence Based Library and Information Practice, 6(2), 75-80. https://doi.org/10.1111/j.14711842.2011.00937.

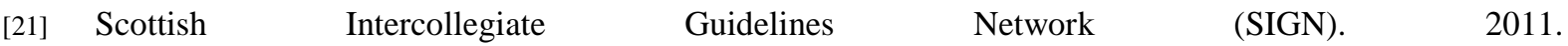
(http://www.show.scot.nhs.uk/sign/guidelines/index.html)

[22] Generic Appraisal Tool for Epidemiology (GATE). 2001. Handbook for the preparation of explicit evidence-based clinical practice guidelines. New Zealand Guidelines Group (NZGG) www.nzgg.org.nz.

[23] Zander, A. (2015). Family Matters Newsletter Portion Size vs. Serving Size: What's the Difference?, 2. Retrieved from www.ext.colostate.edu/

[24] Tanton, J., Dodd, L. J., Woodfield, L., \&Mabhala, M. (2015). Eating Behaviours of British University Students: A Cluster Analysis on a Neglected Issue. Advances in Preventive Medicine, 2015, 1-8. https://doi.org/10.1155/2015/639239

[25] Hilger, J., Loerbroks, A., \& Diehl, K. (2017). Eating behavior of university students in Germany: Dietary intake, barriers to healthy eating and changes in eating behavior since the time of matriculation. Appetite, 109, 100-107. https://doi.org/10.1016/j.appet.2016.11.016

[26] Kinyua, L. W. (2013). Association of nutrition knowledge and attitude with dietary practices and nutritional status of female undergraduate students attending university colleges within Nairobi metropolis.

[27] Al-Isa, A., \&Alfaddagh, A. (2014). Nutritional knowledge among Kuwaiti college students. Health, 06(05), 448-453. doi:10.4236/health.2014.65063.

[28] Manwa, L. (2013.). University Students' Dietary Patterns: A Case of a University in Zimbabwe. Journal of Emerging Trends in Educational Research and Policy Studies (JETERAPS), 4(1). Retrieved from http://citeseerx.ist.psu.edu/viewdoc/download?doi=10.1.1.300.8748\&rep=rep1\&type=pdf

[29] World Health Organization. (2016). Healthy diet. [online] Available at: http://www.who.int/mediacentre/factsheets/fs394/en/ [Accessed 15 May 2016].

[30] Al-Rethaiaa, A. S., Fahmy, A.-E. A., \& Al-Shwaiyat, N. M. (2010). Obesity and eating habits among college students in Saudi Arabia: A cross sectional study. Nutrition Journal, 9(1), 39. doi:10.1186/14752891-9-39

[31] Agriculture, U. S. D. of H. and H. S. and U. S. D. of. (2015). 2015 - 2020 Dietary Guidelines for Americans. $2015-2020$ Dietary Guidelines for Americans (8th Edition), 18. https://doi.org/10.1097/NT.0b013e31826c50af

[32] Poddar, K. H., Hosig, K. W., Anderson, E. S., Nickols-Richardson, S. M., \& Duncan, S. E. (2010). WebBased Nutrition Education Intervention Improves Self-Efficacy and Self-Regulation Related to Increased Dairy Intake in College Students. Journal of the American Dietetic Association, 110(11), 1723-1727. https://doi.org/10.1016/j.jada.2010.08.008

[33] Milosavljevic, D., Mandic, M. L., \&Banjari, I. (2015). Nutritional knowledge and dietary habits survey in high school population. Collegium Antropologicum, 39(1), 101-107.

[34] Kolodinsky, J., Harvey-Berino, J. R., Berlin, L., Johnson, R. K., \& Reynolds, T. W. (2007). Knowledge of current dietary guidelines and food choice by college students: Better eaters have higher knowledge of dietary guidance. Journal of the American Dietetic Association, 107(8), 1409-1413. doi:10.1016/j.jada.2007.05.016

[35] De Vriendt, T., Matthys, C., Verbeke, W., Pynaert, I., \& De Henauw, S. (2009). Determinants of nutrition knowledge in young and middle-aged Belgian women and the association with their dietary behaviour.Appetite, 52(3), 788-792. doi:10.1016/j.appet.2009.02.014

[36] Yahia, N., Achkar, A., Abdallah, A. and Rrizk, S. (2008). Eating habits and obesity among Lebanese university Students. Nutrition Journal 7: 32

[37] Ntuli, Z. (2012). An investigation of socio demographics, nutrition knowledge and dietary intakes of Black students attending the Steve Biko Campus of Durban Institute of Technology.

[38] Al-Nakeeb, Y., Lyons, M., Dodd, L. J., \& Al-Nuaim, A. (2015). An investigation into the lifestyle, health habits and risk factors of young adults. International Journal of Environmental Research and Public Health, 12(4), 4380-4394. https://doi.org/10.3390/ijerph120404380 
[39] Hakim, N., Muniandy, N. and Danish, A. (2012). Nutritional Status and Eating Practices among University Students in Selected Universities in Selangor, Malaysia. Asian Journal of Clinical Nutrition, 4(3), pp.77-87.

[40] Fox, S. (2011). The Social Life of Health Information, Pew Research Center's Internet \& American Life Project.

[41] Andonova, A. (2014). Information and Awareness of the Students ' Healthy Eating, 12, 362-366.

[42] Pollard, C. M., Pulker, C. E., Meng, X., Kerr, D. A., \& Scott, J. A. (2015). Who uses the Internet as a source of nutrition and dietary information? An Australian population perspective. Journal of Medical Internet Research,17(8), e209. doi:10.2196/jmir.4548

[43] Kartam, N., \& Al-Reshaid, K. (2002). Design and implementation of web-based multimedia techniques for construction education. International Journal of Engineering Education, 18(6), 682-696. https://doi.org/10.3946/kjme.2006.18.3.259

[44] Forehand, M. (2012). Bloom's Taxonomy from Emerging Perspectives on Learning, Teaching and Technology. International Journal of Educational Management, 26(2), 205-222. Retrieved from http://0dx.doi.org.alpha2.latrobe.edu.au/10.1108/09513541211202004

[45] Ghirardini, B. (2011). E-learning methodologies: A guide for designing and developing e-learning courses. Food and Agriculture Organization of the United Nations (FAO). https://doi.org/I2516E/1/11.11

[46] Golden, K., Stripp, C., \& Lee, S. (2007). Encouraging student use of feedback, reflection and engagement through web-based learning support. Sciences-New York, 7(2).

[47] Singh, N., Toy, D. R., and Wright, L. K. "A Diagnostic Framework for Measuring Web-site Localization", Thunderbird International Business Review, 51, 3, 281-295, 2009 